\title{
COVID-19 amongst the Pandemic of Medical Student Mental Health
}

Leah Komer. ${ }^{7}$

\section{The Experience}

If being a medical student is hard, being a medical student who struggles with mental health is grueling. Everyday feels like an uphill battle, starting with just getting out of bed after a restless sleep. Just when I thought I was getting a grip on this beast, the unexpected happened. As I was nearing what I thought would be the plateau in this seemingly never-ending climb, COVID-19 sent me up an even steeper path. My original journey had me attending regular counselling sessions and doctors' appointments, with summer electives scheduled, board exams booked, and even small getaways planned with friends. COVID-19 rerouted me to a closed university, no access to counselling services, travel restrictions, a call from the Canadian government to return home, cancelled electives, and oddly, and unpredictably, a toilet paper shortage. While no one was prepared for what the coronavirus pandemic had to bring, it seemed that an already existing problem had been lost in the chaos of it all - what I like to call the pandemic of mental health amongst medical students.

With the demands and pressures that medical students face, it is no surprise that our mental, physical and spiritual wellbeing can be compromised. Ironically, a field that advocates the promotion of health and wellness in patients falls behind in supporting and addressing the needs of its students and residents. In a cross-sectional survey comparing psychological distress and mental illness amongst the medical student population to that of postsecondary graduates, Canadian researchers found that medical students had significantly higher rates of diagnosed mood disorders, suicidal ideation, and psychological distress.' In addition to these higher rates, female medical students were more likely than their male counterparts to have a mood disorder, lifetime suicidal ideation, and more severe psychological distress. ' This is not a unique issue to Canada, and there is a plethora of evidence that medical students worldwide experience significant rates of burnout, psychological distress, and psychiatric morbidity. ${ }^{2-5}$ Despite the abundance of research and blatant problem at hand, in my experience, the support is largely lagging behind the evidence.

Even before the world shut down due to COVID-19, awareness and promotion of mental health in the medical community were difficult to acquire. Throw a viral pandemic into the mix and finding a roll of toilet paper became easier than finding support. With so much uncertainty accompanying the events unfolding globally, the added stress of school responsibilities, cancelled medical placements, board exams, and selfisolation, the weight of it all became too much. I felt like I was succumbing to the beast. I struggled to get out of bed in the morning. I had minimal interactions with friends and family. I would stare at my computer screen for hours on end trying to find the motivation to study. To add fuel to the fire, the expectation was that I would have all this "free-time" to dedicate to my work and that I needed to capitalize on everything shutting down and become immune to the distress the rest of the world was facing. In reality, however, I was struggling with another pandemic. While other students were worried about exams, I was worried about accessing my medication. Amidst medical placements getting cancelled, so were my counselling sessions. I had to uproot from my supports in Ireland to come back home to Canada and self-isolate for 14 days.

I know my situation is not unique. There are thousands of medical students who face similar challenges, and more, on a daily basis, especially now given the evolving COVID-19 situation. I believe that now more than ever, our medical community needs to recognize this and act. Understand that we are more than just students and future healthcare providers, but that we have lives outside of medicine. We are not above the stressors thrown our way due to the global crisis that is unfolding. We are people first and our profession second. Just as our patients need care and support, we owe it to ourselves to return the favour.

1 Medical student, University College Cork, Ireland. 


\section{Experience}

\section{References}

1. Maser B, Danilewitz M, Guérin E, Findlay L, Frank E. Medical Student Psychological Distress and Mental Illness Relative to the General Population: A Canadian Cross-Sectional Survey. Acad Med. 2019 Nov;94(11):1781-1791.

2. Wilkes C, Lewis T, Brager N, Bulloch A, MacMaster F, Paget M, et al. Wellbeing and mental health amongst medical students in Canada. Int Rev Psychiatry. 2019 Nov 17;31(7-8):584-7.

3. Frajerman A, Morvan $\mathrm{Y}$, Krebs MO, Gorwood P, Chaumette B. Burnout in medical students before residency: A systematic review and meta-analysis. Eur Psychiatry. 2019 Jan;55:36-42.
4. Puthran R, Zhang MWB, Tam WW, Ho RC. Prevalence of depression amongst medical students: A meta-analysis. Med Educ. 2016 Apr;50(4):456-68.

5. Quek TTC, Tam WwS, Tran BX, Zhang M, Zhang Z, Ho CSH, et al. The global prevalence of anxiety among medical students: A meta-analysis. Int J Environ Res Public Health. 2019 Jul 31;16(15). pii: E2735.

\section{Acknowledgments}

None

Conflict of Interest Statement at Funding

The Authors have no funding, financial relationships or conflicts of interest to disclose.

Author Contributions

Conceptualization: LK. Writing - Original Draft: LK. Writing - Review and Editing: LK.

Cite as:

Komer L. COVID-19 amongst the Pandemic of Medical Student Mental Health. Int J Med Students. 2020 Jan-Apr;8(1):56-57.

This work is licensed under a Creative Commons Attribution 4.0 International License

ISSN 2076-6327

This journal is published by the University Library System, University of Pittsburgh as part of the Digital Publishing Program and is co-sponsored by the University of Pittsburgh Press. 